\title{
Sickle Cell Disease in Children: An Exploration of Family Resilience through the Experiences of Family Caregivers
}

\author{
Dorothy C. Nwanonyiri', Catherine Jirak Monetti', Sharon Boyd-Jackson² \\ ${ }^{1}$ Department of Nursing, Kean University, Union, NJ, USA \\ ${ }^{2}$ Department of Psychology, Kean University, Union, NJ, USA \\ Email: nwanonyd@kean.edu
}

How to cite this paper: Nwanonyiri, D.C., Monetti, C.J. and Boyd-Jackson, S. (2019) Sickle Cell Disease in Children: An Exploration of Family Resilience through the Experiences of Family Caregivers. Open Journal of Nursing, 9, 347-363.

https://doi.org/10.4236/ojn.2019.94032

Received: February 3, 2019

Accepted: April 5, 2019

Published: April 8, 2019

Copyright (๑) 2019 by author(s) and Scientific Research Publishing Inc. This work is licensed under the Creative Commons Attribution International License (CC BY 4.0).

http://creativecommons.org/licenses/by/4.0/

\begin{abstract}
Background: Sickle cell disease (SCD) is a chronic and potentially life-threatening genetic blood disorder with childhood onset. Caring for children with SCD can precipitate greater than average time demands, medical costs, employment constraints, and childcare challenges. Research has shown that family resilience is a key construct capable of enhancing family health and well-being, as well as neutralizing the burden of caring for an ill child. Aim: Applying the Family Resilience Model, this qualitative study involved exploring the phenomenon of family resilience through the perceptions and lived experiences of family caregivers of children with SCD. Methods: 10 self-identified primary SCD caregivers were recruited with the help of the Sickle Cell Association of New Jersey (SCANJ). Three researches and five open-ended interview questions elicited participants' descriptions of their lived experiences. Results: Using an Interpretive Phenomenological Approach and Donabedian's conceptual model to analyze data, three categories emerged from verbatim transcriptions of interviews: family experiences and caring for a child with SCD (Structure); family strengths (Process); and resilience \& adaptation (Outcome). The emergent theme was Key Family Strengths Fosters Family Resilience and Adaptation. Conclusions: Findings from this study offered insight into the diverse experiences of caring for children with SCD in the framework of family resilience. Results can facilitate the enhancement of family resilience and adaptation for future families and in designing care specifically tailored for these family caregivers. Recognizing resilience processes utilized by family caregivers of children with SCD is important for future research and to render support by healthcare practitioners.
\end{abstract}




\section{Keywords}

Chronic Illness, Family Adaptation, Family Resilience, Sickle Cell Disease

\section{Introduction}

Sickle cell disease (SCD) is a group of potentially life-threatening genetic blood disorders with childhood onset affecting millions of people worldwide [1]. It is an auto-recessive blood disorder and the affected child inherits two abnormal hemoglobin genes from both parents [2] [3]. Abnormal hemoglobin impedes the production of red blood cells in SCD. This causes the normally round red blood cell to become elongated and assume the shape of a crescent [4], which results in the decreased flow of red blood cells through the blood vessels to various parts of the body. Over time, this will lead to painful sickle cell crises, anemia, infections, and multiple organ damage [5].

Being that SCD symptoms begin in childhood, parents and family members become the main caregivers of affected children [6]. Family caregivers of children with SCD experience many demands and challenges that can include, but are not limited to the reorganization of family lives, family conflicts, marital disharmony, and disrupted social and family activities. In addition, families may experience employment instability, financial constraints, regular monitoring and assessments of their children and instituting strategies and preventative measures aimed at reducing triggers and enabling their children to deal with the disease [7] [8] [9] [10]. Furthermore, family caregivers may be burdened with the frequent use of emergency room services, hospitalizations as a result of painful sickle cell crises, stigmatization, stereotyping, blame, misconceptions, and overall poor quality of life and well-being [8] [10] [11] [12] [13].

Caring for children with SCD is a lifelong process that includes home management and the frequent use of healthcare services [14]. As such, most families have both the responsibilities of normal parenting and those related to caring for the ill child. In the United States alone, SCD accounts for an average of 197,000 emergency room visits annually, with a hospitalization rate of 29\% [15]; 113,098 hospital admissions per year; and, $\$ 500$ million in annual medical costs [16]. The disease further accounts for $31.9 \%$ of the hospital 30 -day readmission rate, the highest rate even when compared with heart disease and kidney disease [17]. The medical costs for the over 70,000 people affected by SCD in the United States are estimated to exceed $\$ 1.1$ billion annually [14]. Unhealthy family functioning can lead to several other medical and mental health issues, such as behavioral disturbances and poor quality of life [18].

The management of SCD remains basic and suboptimal. It is usually geared toward pain management, hydration, the prevention of infection with prophylactic penicillin, and the avoidance of triggers such as cold or hot weather and trauma [19]. Treatment modalities include blood transfusions and, most recently, the use of hydroxyurea [20]. Hydroxyurea is a relatively new chemotherapeu- 
tic agent that decreases the frequency of painful crises, blood transfusions, acute chest syndrome (ACS), and hospitalization [21]. There is currently no definitive cure for SCD except for costly and often inaccessible bone marrow transplant and gene therapy [22].

These demands and challenges can compromise the caregiver's health and well-being and consequently impair family functioning. However, family resilience defined as family traits or characteristics that help family members overcome difficulties and survive the daily life challenges of caring for an ill family member can help minimize these challenges [23]. It is assumed that the ways in which a family deals with these challenges will ultimately affect family functioning, caregiver overall health, and child outcomes. Therefore, it is important to understand the practices and processes which help family caregivers of children with SCD to buffer these challenges and attain positive outcomes in the face of such a stressful life event.

\section{Theoretical Framework}

The Family Resilience Model (FRM) is the theoretical framework that guided this study [24]. It serves as a conceptual map to identify key factors that clinicians can facilitate to strengthen family resilience [25]. The ways in which families work together to acquire information and skills and to process the information are important aspects of family resilience [26]. Family resilience plays a role in exploring family relationships, surviving a crisis, creating opportunities for growth out of adversity, and developing skills to share with other people experiencing similar situations [27]. Family resilience is operationalized as a process that occurs over time rather than a trait [24] [28]. It creates an avenue for identifying and fostering key family strengths and resources that have the ability to reduce stress and vulnerability in high-risk situations, enhance healing and growth out of crises, and allow families to overcome prolonged adversity [24].

The FRM is relational and contextual because it views family crises through a positive resilience lens, highlighting the resources families possess that influence their ability to rebound from disruptive life experiences [24] [29]. Another premise is that family resilience enables the family to be compassionate in seeking to understand parental life challenges, foster harmonious relationships, and look for unrecognized strengths among family members [30]. No single trait defines a resilient family [24] [30] [31]. However, three basic dimensions of strengths and resources enable them to rally together in times of crisis to buffer stress and minimize family dysfunction: 1) family belief systems; 2) family organizational patterns; and 3) communication and problem solving (see Figure 1). They enable the family to survive and thrive in the face of suffering, decrease the risk of dysfunction, and foster positive adaptation [31].

\section{Methods}

\subsection{Design}

To explore the phenomenon of family resilience and gain a better understanding 


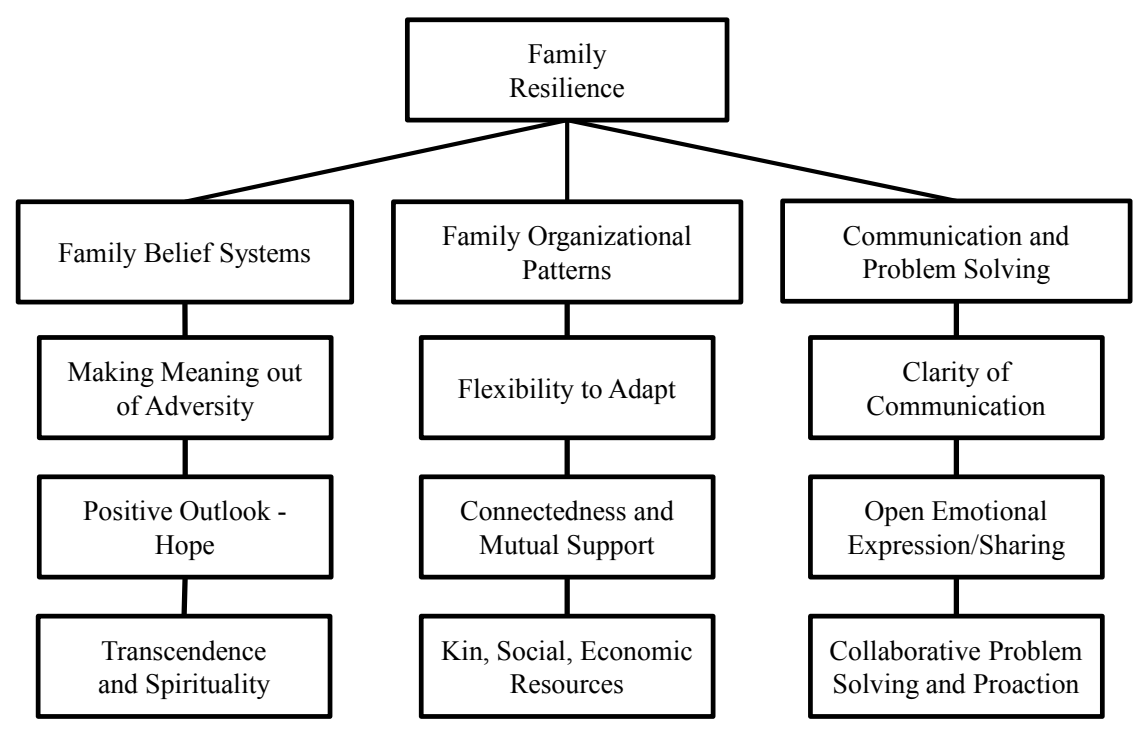

Figure 1. Family resilience model [24].

through the lived experiences of SCD family caregiver, a qualitative research design was utilized. Qualitative research allows for a deeper understanding of the lived experiences of study participants [32]. As stated by Reference [33], "To understand SCD caregivers' experiences, personal stories must be elicited to capture their human experiences" (p. 2).

\subsection{Sampling}

Participants for this study were selected through purposive and snowball sampling with the help of Sickle Cell Association of New Jersey (SCANJ) for a period of 3 months from December through March. Participants were intentionally recruited as they had experiences with caring for a child with SCD. Participants included 10 self-identified primary caregivers of children with SCD $(n=9$ mothers, $n=1$ father) who were between the ages of 23 to 48 years. The justification for this sample size was based on the recommendation of sample size of 5 - 25 as adequate for a qualitative study. In addition, this sample size was accepted once data saturation was noted [32]. This sample size is adequate for data gathering in an interpretive phenomenological analysis (IPA) study [34] because it is in-depth and time-consuming as the concern is with gaining complete insight into each participant's narrative. Each participant met the following inclusion criteria: be between the ages of 18 and 75 years old, lived in the same household as the child with SCD, served as the primary caregiver to the child, and communicated in English. The requirement to communicate in English was important for data gathering and transcription. Participants were excluded if they are not the primary caregivers of the child and if the child did not live in the same household as the participant.

\subsection{Data Collection}

This study was approved by Kean University Institutional Review Board (IRB). 
Permission to conduct research was also obtained from SCANJ. In addition, the researcher obtained approval from the Kean University Center for Leadership and Service to recruit participants through Kean University by placing flyers around the university premises. Once interested participants contacted the researcher, a brief telephone interview was conducted to ensure eligibility. After establishing eligibility, the researcher explained the study and its purpose to the potential participants. Participants were informed that there were no direct benefits for participating in the study. Once the potential participant expressed continued interest and agreed to participate, an interview date and time was scheduled according to the participant's availability.

Prior to beginning any interview participants were informed of their rights which included that participation in the study was strictly voluntary, they had the right to refuse to answer any question or discuss anything that would cause them any emotional discomfort as well as the right to terminate the interviews at any time without questions asked. Interviews were conducted at public facilities in private offices. To maintain confidentiality and anonymity, each participant received a unique identifying code (e.g., P1-P10). Though the participants used their names on the Informed Consent forms, no other forms directly linked their identities.

Interview questions were semi-structured and open-ended. This allowed the participants to give as much detailed information as they felt necessary to answer the questions and allowed the researcher to ask probing questions [35]. Interviews lasted approximately 30 to 45 minutes. Interviews continued until data saturation was reached; that is, when there were no more repetitive and abundant themes and categories emerging and the data collection process no longer offered any new or relevant data [36] [37]. To eliminate bias the audio recordings were immediately sent to a third party not familiar with the study for verbatim transcription.

\subsection{Data Analysis}

The researcher used the Interpretative Phenomenological Analysis (IPA) approach for data analysis [38]. The use of an IPA approach allowed the study participants to share their lived experiences and stories as they chose without any distortion [39]. Data analysis began by reading each verbatim transcript in totality, and then re-reading them several times. Field notes were reviewed. While reading the transcripts individually and listening to the audio recordings, the researcher made notes on the margins and identified significant and recurrent themes, similar language, and ideas. Any significant statements made by participants and noted themes with relevance to the research questions were coded. Coding was used to identify the themes, problems, similarities, and dissimilarities presented through the participants' stories and interpreted by the researcher [40]. Once coding was completed, the codes were further analyzed across all data. Similar codes from each participant were grouped together and categorized. To ensure qualitative rigor and a more in-depth thematic analysis, a 
second level data analysis was conducted using NVivo software. This analysis identified common themes across the data that addressed the research questions. The researcher used open coding, which involved using a brainstorming technique described by Reference [41] to "open up the data to all potentials and possibilities contained within them" (p. 160).

\section{Findings}

\subsection{Participant Demographics}

Study participants consisted of a diverse population of nine mothers and one father. The father identified as immigrant from Nigeria while the mothers consisted of African American $(n=2)$ and immigrants from West African countries such as Nigeria $(n=3)$, Cameroon $(n=1)$, and Ghana $(n=2)$. One participant identified as being from the West Indies $(n=1)$ and another identified as being from Haiti $(n=1)$. Two other African American family caregivers of children with SCD expressed a willingness to participate in the study but later cancelled because their children were hospitalized. Table 1 provides a snapshot of the participant demographics.

\subsection{Thematic Analysis}

Based on the FRM [24], the study queried:

Table 1. Demographic characteristics of participants $(N=10)$.

\begin{tabular}{|c|c|c|}
\hline Variable & $N$ & $\%$ \\
\hline \multicolumn{3}{|l|}{ Gender } \\
\hline Male & 1 & 10 \\
\hline Female & 9 & 90 \\
\hline \multicolumn{3}{|l|}{ Religion } \\
\hline Christian & 3 & 30 \\
\hline Catholic & 7 & 70 \\
\hline \multicolumn{3}{|l|}{ Marital Status } \\
\hline Married & 8 & 80 \\
\hline Never Married & 1 & 10 \\
\hline Divorced & 1 & 10 \\
\hline \multicolumn{3}{|l|}{ Race } \\
\hline African American & 10 & 100 \\
\hline \multicolumn{3}{|l|}{ Highest Level of Education Completed } \\
\hline High School & 2 & 20 \\
\hline College & 8 & 80 \\
\hline Employed & 10 & 100 \\
\hline Living in the Same Household as Child & 10 & 100 \\
\hline Primary Caregiver & 10 & 100 \\
\hline
\end{tabular}


1) What are family experiences of caring for children with SCD?

2) What strategies do family caregivers of children with $S C D$ use to deal with their experiences so they can effectively adapt?

3) What family resilience processes are essential for successful adaptation among family care givers of children with SCD?

All study participants were asked the following open-ended questions to elicit their SCD caregiver experiences and family resilience factors they utilize and considered essential for successful adaptation: 1) Tell me about your family experiences in caring for the child in your family identified with SCD. 2) Please tell me about your family beliefs that help your family when dealing with experiences related to taking care of the child with SCD. 3) Please tell me about the ways your family organizes the family unit as they deal with the experiences associated with caring for the child with SCD. 4) How does your family communicate and problem-solve when responding to their experiences from taking care of the child with SCD? 5) What are the things your family does that you find helpful in dealing with your experiences in taking care of your child with SCD?

Focusing on the three research questions, the coding process revealed three categories and ten subcategories: 1) family experiences of caring for a child with SCD-(structure): experiences of caregivers, experiences of the child, family challenges, 2) family strengths (process) - communication, empathy/sympathy, family/social support, and 3) resilience \& adaptation (outcome)-coping, medical management, child advocacy, and spiritual/religious beliefs. The findings for each theme are summarized below with the use of exemplar quotes.

Theme 1: family experiences of caring for a child with SCD

The primary themes were: a) it is emotionally difficult for families; b) families experience psychological stress; $c$ ) families experience financial stress; d) families experience a disruption in family dynamics; e) families experience arguments; $f$ ) families experience fear; g) SCD affects the child's self-efficacy; h) families have little time; and, i) families experience burnout.

It is emotionally difficult for families. Caregivers mentioned the emotional difficulties they experience in terms of the family and watching the child experience pain without been able to help. $\mathrm{P} \# 10$ shared: The hardest part is not understanding what it feels like when they' re in pain or having a crisis and wanting to take the pain away from them so they don't feel that... So, it's kind of hard to sit and watch your kid in pain when you have to wait to get medication administered. You get frustrated.

P\#6 explained: Emotionally we always like, we don't want to see her in so much pain. It makes us so sad to see her at times. We even fight about, we blame ourselves like, I don't know how this happened, how she's in so much pain.

Families experience psychological stress. Participants described their experience in caring for their child with SCD as one that is associated with a high of psychological stress. P\#7 explained: Just escalated distress and the worry of when next she is going to be sick, and then I always worry about how is my son, her brother, affected in school, because his life is upside down too when I am in the 
hospital. He comes from school there, eats all the junk food in the hospital, goes home around 12, then goes to school, for that period she is in the hospital.

Families experience financial stress. As described by family caregivers, their financial stress usually related to the parents not being able to work or losing income. $\mathrm{P} \# 8$ said:

I could be in the middle of a shift and he will start going into crisis and once you receive that call from home, you have to make arrangements to cover your shift. Depending on how many days he ends up staying in the hospital, you will have to stay there with him. So, that cuts from the income also.

Families experience a disruption in family dynamics. Caregivers also shared the disruption in other family members' lives and activities as a result of caring for their child.

Participant \#8 shared: "I could not and nobody in my family can really do anything without having the fear in the back of our minds who knows when the crisis will come because you never get the advanced notice that it's going to come at any specific time."

Families experience arguments. In this theme, caregivers described the disharmony, arguments, and disagreements that occurred within the family unit because of caring for the child with SCD.

Participant \#6 said, we even fight about, we blame ourselves like, I don't know how this happened, how she's in so much pain. Similarly, P\#9 stated: Most times there's a lot of disagreement, of course, especially between my husband and myself. I become very irritable and sometimes I do not even want to talk to people. You just want to stay by yourself. Basically, my whole family is torn apart because of this.

Families experience fear. Family caregivers reported their family members experienced fear and worry about the child becoming ill at any time. P\#3 explained feeling fearful: It is like you are always on the edge. You don't know when he is going to get sick again, and you don't know when you are going to get that call, so your job becomes second priority.

Sickle cell disease affects the child's self-efficacy. This theme discussed the impact of the disease on the child's self-efficacy and mental state. P\#4 shared; it is challenging for her as a child. She is only 10 years old, and it is challenging for us as a family, because she feels that her other siblings are doing more sports than her, which is very heartbreaking at times.

Families have little time. The experience mentioned here was that of families having little time for other activities and for the ill child's siblings. P\#9 expressed; I cannot even do what women my age do. So, it's very stressful of course on my family. At some point I know they probably feel neglected because all of the attention is going to the sick child. Myself as a woman sometimes I feel like $P m$ not giving enough attention to the other kids. So, it s sough.

Families experience burnout. This theme refers to the families caring for a child with SCD experiencing burnout and exhaustion. $\mathrm{P} \# 5$ shared: This disease is no joke. It has impacted my family in several ways. One of the days I actually 
took my daughter to the movie theater. She had an episode there and a crisis and she had to [go] straight to the hospital. It is very, very exhausting.

Theme 2: family strengths

The eight primary themes were: a) use religion, prayer, faith, and spiritual practices; b) use non-medical remedies; c) family members chip in; d) rely on medical treatment; e) get educated about the disease; f) hope for healing; g) do not disclose SCD; and, h) support from outside the family.

Use religion, prayer, faith, and spiritual practices. Caregivers identified religion, prayer, faith, and spiritual practices as a strategy which helps them deal with their experiences so they can effectively adapt. P\#4 mentioned, "From the very first, our faith and our spirituality is very important to us in all we do. So being Christians and believing in God and believing in healing is very helpful to us."

Use non-medical remedies. This theme refers to family caregivers of children with SCD using other non-medical remedies, such as essential oils, herbs, and spices, to help alleviate the child's pain during sickle cell crisis. Consequently, these non-medical remedies helped caregivers to adapt more effectively\#10 states; my grandma mixes nutmeg and coconut oil and all these different spices and herbs and she rubs his body down with it. She rubs in his head and nose and underneath his feet and stuff. She also gives him frozen water with like lemon and stuff on it to pat his head and stuff like that. It worked.

Family members chip in. This theme refers to family caregivers of children with SCD relying on family members to help and provide social support to deal with SCD experiences so they can effectively adapt. P\#9 shared; Sometimes when she needs to see a consultant or something and probably $1 \mathrm{~m}$ just like too tired and like today I cannot move I have a niece or a nephew come take the child and take her to the appointment and take it from there if my husband is not available. Once in a while they do step in. I don't like to ask but when it gets tough there's always someone willing to help.

Rely on medical treatment. This theme refers to family caregivers of children with SCD relying on medical treatment to manage the SCD experiences so they can effectively adapt. $\mathrm{P} \mathbf{6}$ described how their family relied on medical treatment: My family strengths, we make sure she gets her immunizations. We make sure she takes her medication. We make sure she goes to doctor's appointments. She goes to very often.

Get educated about the disease. This theme refers to family caregivers of children with SCD getting educated about the disease to deal with SCD experiences so they can effectively adapt.

P\#6 said: We make sure that we read up about the illness and then whenever she's in pain, we make sure that we take care of her. We give her meds and then if the pain doesn't go away, we take her to the emergency.

Hope for healing. This theme refers to family caregivers hope for healing or a cure to deal with SCD experiences so they can effectively adapt.

$\mathrm{P} \# 6$ expressed: We believe that she's going to get better... Mostly what I would 
say that is particular to my family is our belief in god that the sickness will go away. My belief now is that God is going to take this illness away in order that she will one day outgrow it. That's one thing I believe.

Do not disclose SCD. This theme refers to family caregivers not disclosing the child's illness to avoid stigma so they can effectively adapt. P\#9 described not disclosing the SCD diagnosis to avoid stigma: Well, we only talk about the experience within our family or those who know us and our friends. But people who we' re not comfortable with we don't talk about the illness with them because most of the time she don't want people to judge you because you get to hear oh you should have known that you have AS, your husband has AS that things like this would happen. We don't want to deal with the judgment issue and the stigma that comes, you know, we don't want the child to feel the stigma that comes with having sickle cell disease.

Support from outside the family. This theme refers to family caregivers using support from outside the family as a strategy to deal with SCD experiences so they can effectively adapt.

P\#5 shared: "we have a women's group in the church. They are very, very helpful and very, very supportive to me and my family. So, we really count on their support most of the times."

Theme 3: resilience \& adaptation

The five primary themes were: a) having spiritual beliefs and practices are essential; b) having support network is essential; c) being an advocate for medical care is essential; d) communication among family members is essential; and, e) finding a way to cope with the stress is essential.

Having spiritual beliefs and practices is essential. All study participants shared that one thing they found essential in dealing with the experiences of caring for their child with SCD was their spiritual beliefs and practices. This was described in the form of their spirituality, religion, being prayerful, having faith/trust in God, belief in a higher being, and belief in God. Most participants shared engaging in prayer and believing God would help them get through their challenges regardless of how bothersome it may seem.

Having support network is essential. This theme refers to family caregivers of children with SCD relying on family members, church members, and social networks to chip in and provide support to deal with SCD experiences so they can effectively adapt. Almost all participants identified some degree of support from family members (immediate and extended family members), church groups, and social networks as essential for successful adaptation in dealing with their experiences.

Being an advocate for medical care is essential. This theme refers to families advocating for the medical care the child needed as being essential for successful adaptation among family caregivers of children with SCD. P\#10 expressed; As a parent with a child you know your child so you should never let someone else tell you what's going on with your child when you are there with them mostly 24/7 to see and to know when they' re going through a crisis or even 
having a fever or any kind of symptoms that they' re having. You can't let somebody else tell you that's not what it is when that's what you know in your heart that's what's going on with your child. You have to advocate and stand firm in what you believe that's going on with your child.

Communication among family members is essential. This theme refers to open communication among family members being essential for successful adaptation. Most study participants shared the importance of been open-minded things, being able to talk and express one's feeling or emotions as essential in facilitating adaptation.

We've decided that we have to do an open communication. If you're feeling that you're being burdened a lot, if you are feeling that you're carrying the load more you have to talk with the other persons. So, we all share everything. We share the communication; we share our burdens with each other by talking it out. You have to speak it out; you have to talk with everybody.

Finding ways to cope with the stress is essential. This theme refers to finding a way to cope with the stress being essential for successful adaptation. Caregivers reported that they engage in exercises; use essential oils, eucalyptus oil or something with vanilla oil as aromatherapies to "de-stress". This was reported to be a strategy that was essential in successful family adaptation.

\section{Discussion}

Study findings revealed SCD family caregivers experience a variety of challenges related to their caregiving role. In juxtaposition, this study also highlighted the practices they found helpful in dealing with those experiences and challenges. Uniquely, study findings offered insight into their diverse lived experiences in the framework of family resilience. This study finding can enhance family resilience and family adaptation for future families, and inform the design of tailor-made interventions for them.

Study findings addressed each of the three research questions. For research question one, SCD caregivers described their family experiences as being associated with emotional difficulty, burnout, psychological and financial stress, disruptions in family dynamics, relationship conflicts, and family disharmony. More than half of all study participants expressed some degree of blame, uncertainty, and fear the child would die; shame and secrecy; and hope for healing and a cure. Noteworthy was the participants' report of additional negative emotions that can lead to maladaptive behaviors (e.g., lack of disclosure or denial of diagnosis; living in secrecy).

For research question 2, participants shared the strategies they employed in dealing with SCD experiences so they can effectively adapt: religion and prayer, relying on both non-medical and medical approaches, being knowledgeable about the disease process, hoping for healing and a cure, keeping the child's illness a secret and family collaboration and support.

Regarding research question 3, results showed that despite the numerous 
challenges described by SCD family caregivers, they were able to develop and identify diverse family resilience processes that were cultivated over time. This was consistent with the proposition that when faced with stressful life events or adversity, family members and caregivers employ a set of processes to deal with the situation [24]. Focusing on positive adaptation enables distressed families to be viewed with respect and compassion for their struggles and supports their ability to rebound from their challenges by bringing out their best qualities [24]. This study also revealed there is great need to understand the lived experiences of family caregivers of children with SCD and understand the desire of families affected by SCD to find a cure for this devastating illness.

Using the FRM as a guiding framework illustrates how families might adapt to the experiences of caring for a child with SCD through a series of inter-related practices [24]. A singular model cannot measure family function. Family assessment should include their values, structure, resources, and life challenges [42]. Findings from this study corroborated the FRM, which states that families possess resources that influence their ability to rebound from disruptive life experiences [24]. The framework is useful as a means of looking at families as resourceful when dealing with stressful life events and adversities rather than destroyed by their experiences [24]. Families emerge stronger and more resourceful in facing future stressors and challenges [43].

A family resilience framework sheds light into how caregivers cope, adapt, and become proficient when dealing with adversity [44]. The emphasis on family resilience in research and clinical practice offers researchers and practitioners the opportunity to identify and support behaviors and moderating effects that enable families to cope more effectively and emerge resilient from crises or persistent stressors [45].

Study findings contribute to the practice application of family resilience when assessing family caregivers of children with SCD. It enables practitioners to assess families as having common characteristics but at the same time recognize their unique strengths and weaknesses, as well as different pathways and solutions to related problems [45]. For nurses, identifying family strengths and resilience factors during stressful life events can inform the choice of nursing interventions to meet a family's needs [46]. Therefore, when performing health screenings with caregivers of children with SCD, the nurse must affirm their family strengths. It is also important to consider a family's cultural values, social location, economic status, and developmental concerns [31]. Finally, a framework highlighting key family resilience processes may lead to the creation and implementation of community-based programs and training programs for healthcare professionals [31] [47].

\section{Conclusions}

Using an IPA approach [38], the researcher was able to identify several themes related to family caregivers' experiences in caring for children with SCD and the 
family resilience processes they considered essential for successful family adaptation. Study findings revealed that SCD family caregivers developed resilience through processes such as having spiritual beliefs and practices, having a support network, being an advocate for medical care, having open communication among family members, and finding ways to cope with the stress. These findings aligned with the FRM [24] and highlighted the significance of using this framework as a guide in exploring family experiences in dealing with stressful life events.

Interestingly, nine participants described their caregiving experiences as having a negative effect on family functioning. In contrast, one participant described her family experience as challenging but manageable. This participant shared how the family did not view the child as sick and described positive family experiences with daycare. Similarly, more than half of the participants discussed the psychological impact associated with caring for their child. However, only one participant made mention of medical diagnoses; namely, hypertension with depression. One might expect that caregivers of children with SCD would discuss a number of physiological symptoms either resulting from or exacerbation by caring for their child. This may shed some light on how caregivers minimize the impact of their caregiving role.

This study highlighted the importance of continual conversation concerning the emotional impact of guilt, shame, living in secrecy, and denial. The researcher puts forward that social stigma facilitates guilt associated with SCD. Combined, the guilt and social stigma readily lead to feelings of shame. In addition, cognitive dissonance, which is having two conflicting thoughts, can occur when living in secrecy. The family attempts to hide the diagnosis from society, or as individuals. Albeit maladaptive, these approaches serve as emotional protection for the child and his or her caregivers. In addition, the strategy of denial may enable the family caregivers to preserve family dignity. On the other hand, denial and rejection of the SCD diagnosis may actually support hope and faith in God; more specifically, a belief that God will heal the child or the child will outgrow the illness.

Although there are recognizable similarities in SCD caregivers' experiences, there are also notable variations in how caregivers deal with them. Hearing the stories of how family caregivers of children with SCD deal with and adapt to the challenges they face as a result of their child's illness can help to develop tailored programs that may help other families overcome the challenges with better adaptation.

\section{Limitations}

Although the qualitative findings provided thick, rich description of SCD caregivers' lived experiences, several limitations exist. Purposive sampling may have biased the sampling process because the study participants self-selected for study participation. Recruitment was limited to those caregivers known to the SCANJ 
agency and caregivers who were willing to share their experiences.

Another limitation was that data obtained from the participants (family representatives) were based on the primary caregiver's perception and the extent of information they were willing to divulge. Participants may have responded in ways they thought the researcher wanted them to respond. In addition, participants may have feared exposure of their (family) information that is not known to the agency. This may have resulted in untruthful or censored information. The sample size for this study was adequate; however, it does not epitomize the larger population of family caregivers of children with SCD. The small sample size may also have jeopardized data saturation.

\section{Recommendations for Future Research}

Continued family resilience research can produce intervention and preventive strategies that will strengthen family processes. Since study participants were primarily mothers of children with SCD, future studies to explore the family resilience experiences of fathers of children with SCD and other family members using different family structures. This could produce an all-inclusive view of positive family adaptation. In addition, an exploration of the effect of family resilience on the quality of life and health outcomes of children with SCD (i.e. the number of sickle cell crises) is warranted.

Many study participants spoke about secrecy and failure to disclose their child's illness due to fear of societal stigma. Future research should include qualitative studies exploring caregivers' perceptions of societal stigma and quantitative studies investigating the effect of societal stigma on caregivers' health and attitudes. Results also showed caregivers of children with SCD do not talk about the impact of their caregiving experiences in terms of their physical health and well-being. Therefore, their quality of life should be quantitatively assessed. Finally, participants expressed a need for research on genetic education, screening, and counseling among individuals of reproductive age.

\section{Acknowledgements}

I would like to extend my sincerest gratitude to the families who shared their stories and experiences. I would also like to express my warmest gratitude to the Sickle Cell Association of New Jersey for the work they do on behalf of the sickle cell community and for assisting me in reaching some of the families whose stories we share.

\section{Conflicts of Interest}

The authors declare no conflicts of interest regarding the publication of this paper.

\section{References}

[1] Centers for Disease Control and Prevention (2016) Facts about Sickle Cell Disease. 
https://www.cdc.gov/ncbddd/sicklecell/facts.html

[2] Galadanci, N., et al. (2014) Current Sickle Cell Disease Management Practices in Nigeria. International Health, 6, 23-28. https://doi.org/10.1093/inthealth/iht022

[3] Sickle Cell Disease Association of America (N.D.) About SCT \& SCD. https://www.sicklecelldisease.org/about/sickle-cell-101/

[4] Williams-Gray, B. and Senreich, E. (2015) Challenges and Resilience in the Lives of Adults with Sickle Cell Disease. Social Work in Public Health, 30, 88-105. https://doi.org/10.1080/19371918.2014.938396

[5] Owotomo, J. (2016) The Socioeconomic and Cultural Impact of Sickle Cell Disease in Nigeria. PhD Thesis, Walden University, Minneapolis.

[6] Burnes, D.P.R., Antle, B.J., Williams, C.C. and Cook, L. (2008) Mothers Raising Children with Sickle Cell Disease at the Intersection of Race, Gender, and Illness Stigma. Health \& Social Work, 33, 211-220. https://doi.org/10.1093/hsw/33.3.211

[7] Enemmuo, V.C. (2017) The Lived Experience of Parents of Nigerian Children with Sickle Cell Disease. PhD Thesis, University of Phoenix, Phoenix.

[8] Gesteira, E.C.R., Bousso, R.S., Misko, M.D., de Faria Ichikawa, C.R. and de Oliveira, P.P. (2016) Families of Children with Sickle Cell Disease: An Integrative Review. Online Brazilian Journal of Nursing, 15, 276-290.

[9] Murray, C.E., Kelley-Soderholm, E.L. and Murray, T.L., Jr. (2007) Strengths, Challenges, and Relational Processes in Families of Children with Congenital Upper Limb Differences. Families, Systems, \&Health, 25, 276-292. https://doi.org/10.1037/1091-7527.25.3.276

[10] Wonkam, A., et al. (2014) Psychosocial Burden of Sickle Cell Disease on Parents with an Affected Child in Cameroon. Journal of Genetic Counseling, 23, 192-201. https://doi.org/10.1007/s10897-013-9630-2

[11] Brown, B.J., et al. (2010) Burden of Health-Care of Carers of Children with Sickle Cell Disease in Nigeria. Health \& Social Care in the Community, 18, 289-295. https://doi.org/10.1111/j.1365-2524.2009.00903.x

[12] Jenerette, C., Brewer, C.A., Crandell, J. and Ataga, K.I. (2012) Preliminary Validity and Reliability of the Sickle Cell Disease Health-Related Stigma Scale. Issues in Mental Health Nursing, 33, 363-369. https://doi.org/10.3109/01612840.2012.656823

[13] Wesley, K.M., Zhao, M., Carroll, Y. and Porter, J.S. (2016) Caregiver Perspectives of Stigma Associated with Sickle Cell Disease in Adolescents. Journal of Pediatric Nursing, 31, 55-63. https://doi.org/10.1016/j.pedn.2015.09.011

[14] Raphael, J.L. and Oyeku, S.O. (2013) Sickle Cell Disease Pain Management and the Medical Home. Hematology, 2013, 433-438. https://doi.org/10.1182/asheducation-2013.1.433

[15] Wilson, B.H. and Nelson, J. (2015) Sickle Cell Disease Pain Management in Adolescents: A Literature Review. Pain Management Nursing, 16, 146-151. https://doi.org/10.1016/j.pmn.2014.05.015

[16] Weisberg, D., Balf-Soran, G., Becker, W., Brown, S.E. and Sledge, W. (2013) "I'm Talking about Pain": Sickle Cell Disease Patients with Extremely High Hospital Use. Journal of Hospital Medicine, 8, 42-46. https://doi.org/10.1002/jhm.1987

[17] Clayton-Jones, D. and Haglund, K. (2016) The Role of Spirituality and Religiosity in Persons Living with Sickle Cell Disease: A Review of the Literature. Journal of Holistic Nursing, 34, 351-360. https://doi.org/10.1177/0898010115619055

[18] Exum, K.L. (2013) The Effects of Family Functioning on Academic Achievement in Children with Sickle Cell Disease. PhD Thesis, East Carolina University, Greenville, 
North Carolina.

[19] Hildenbrand, A.K., Barakat, L.P., Alderfer, M.A. and Marsac, M.L. (2015) Coping and Coping Assistance among Children with Sickle Cell Disease and Their Parents. Journal of Pediatric Hematologyl Oncology, 37, 25-34. https://doi.org/10.1097/MPH.0000000000000092

[20] Manwani, D. and Frenette, P.S. (2013) Vaso-Occlusion in Sickle Cell Disease: Pathophysiology and Novel Targeted Therapies. Blood, 122, 3892-3898. https://doi.org/10.1182/blood-2013-05-498311

[21] Creary, S., Zickmund, S., Ross, D., Krishnamurti, L. and Bogen, D.L. (2015) Hydroxyurea Therapy for Children with Sickle Cell Disease: Describing How Caregivers Make this Decision. BMC Research Notes, 8, 372. https://doi.org/10.1186/s13104-015-1344-0

[22] Chakravorty, S. and Williams, T.N. (2015) Sickle Cell Disease: A Neglected Chronic Disease of Increasing Global Health Importance. Archives of Disease in Childhood Education and Practice Edition, 100, 48-53. https://doi.org/10.1136/archdischild-2013-303773

[23] Amagai, M., Takahashi, M. and Amagai, F. (2016) Qualitative Study of Resilience of Family Caregivers for Patients with Schizophrenia in Japan. Mental Health in Family Medicine, 12, 307-312.

[24] Walsh, F. (2003) Family Resilience: A Framework for Clinical Practice. Family Process, 42, 1-18. https://doi.org/10.1111/j.1545-5300.2003.00001.x

[25] Becvar, D.S. (2012) Handbook of Family Resilience. Springer Science \& Business Media, New York.

[26] West, C., Usher, K. and Foster, K. (2011) Family Resilience: Towards a New Model of Chronic Pain Management. Collegian, 18, 3-10. https://doi.org/10.1016/j.colegn.2010.08.004

[27] Appleby, J.M. (2014) Resilience in Families of Children Who Have Disabilities. PhD Thesis, The University of Texas at Arlington, Arlington, Texas.

[28] Simon, J.B., Murphy, J.J. and Smith, S.M. (2005) Understanding and Fostering Family Resilience. The Family Journal, 13, 427-436. https://doi.org/10.1177/1066480705278724

[29] Cripe, C.T. (2013) Family Resilience, Parental Resilience and Stress Mediation in Families with Autistic Children. PhD Thesis, Northcentral University, Scottsdale, Arizona.

[30] Walsh, F. (2006) Strengthening Family Resilience.2nd Edition, Guilford Press, New York.

[31] Walsh, F. (2016) Strengthening Family Resilience. 3rd Edition, Guilford Press, New York.

[32] Creswell, J.W. (2007) Qualitative Inquiry and Research Design: Choosing among Five Approaches. 2nd Edition, Sage, Thousand Oaks.

[33] Garrett, K.C. (2014) Sickle Cell Disease and the Family: A Phenomenological Study. PhD Thesis, Kansas State University, Manhattan, Kansas.

[34] Pietkiewicz, I. and Smith, J.A. (2014) A Practical Guide to Using Interpretative Phenomenological Analysis in Qualitative Research Psychology. Psychological Journal, 20, 7-14.

[35] Turner, D.W. (2010) Qualitative Interview Design: A Practical Guide for Novice Investigators. The Qualitative Report, 15, 754-760. 
[36] Dworkin, S.L. (2012) Sample Size Policy for Qualitative Studies Using In-Depth Interviews. Archives of Sexual Behavior, 41, 1319-1320. https://doi.org/10.1007/s10508-012-0016-6

[37] Polit, D.F. and Beck, C.T. (2008) Nursing Research: Generating and Assessing Evidence for Nursing Practice. Lippincott Williams \& Wilkins, Philadelphia.

[38] Smith, J.A., Flowers, P. and Larkin, M. (2009) Interpretative Phenomenological Analysis. Sage, London.

[39] Alase, A. (2017) The Interpretative Phenomenological Analysis (IPA): A Guide to a Good Qualitative Research Approach. International Journal of Education \& Literacy Studies, 5, 9-19. https://doi.org/10.7575/aiac.ijels.v.5n.2p.9

[40] Sutton, J. and Austin, Z. (2015) Qualitative Research: Data Collection, Analysis, and Management. The Canadian Journal of Hospital Pharmacy, 68, 226-231. https://doi.org/10.4212/cjhp.v68i3.1456

[41] Corbin, J.M. and Strauss, A.L. (2008) Basics of Qualitative Research: Techniques and Procedures for Developing Grounded Theory. 3rd Edition, Sage, Los Angeles. https://doi.org/10.4135/9781452230153

[42] Walsh, F. (2002) A Family Resilience Framework: Innovative Practice Applications. Family Relations, 51, 130-137. https://doi.org/10.1111/j.1741-3729.2002.00130.x

[43] Walsh, F. (2011) Family Resilience: A Collaborative Approach in Response to Stressful Life Challenges. In: Southwick, S.M., Charney, D. and Friedman, M.J., Eds., Resilience and Mental Health: Challenges across the Lifespan, Cambridge University Press, Cambridge, 149-161. https://doi.org/10.1017/CBO9780511994791.012

[44] Blacher, J. and Hatton, C. (2007) Families in Context: Influences on Coping and Adaptation. In: Odom, S.L., Horner, R.H., Snell, M.E. and Blacher, J., Eds., Handbook on Developmental Disabilities, Guilford Press, New York, 531-551.

[45] Hooper, L.M. (2009) Individual and Family Resilience: Definitions, Research, and Frameworks Relevant for all Counselors. Alabama Counseling Association Journal, 35, 19-26.

[46] West, C., Buettner, P., Stewart, L., Foster, K. and Usher, K. (2012) Resilience in Families with a Member with Chronic Pain: A Mixed Methods Study. Journal of Clinical Nursing, 21, 3532-3545. https://doi.org/10.1111/j.1365-2702.2012.04271.x

[47] Jenerette, C., Brewer, C.A., Silva, S. and Tanabe, P. (2016) Does Attendance at a Sickle Cell Educational Conference Improve Clinician Knowledge and Attitude Toward Patients? Pain Management Nursing, 17, 226-234. https://doi.org/10.1016/j.pmn.2016.05.001 